Lepr Rev (1983) 54, 217-227

\title{
Immune responses to bovine neural antigens in leprosy patients. II. Absence of in vitro lymphocyte stimulation to peripheral nerve myelin proteins*
}

\author{
R N MSHANA, D P HUMBER, M HARBOE $\dagger$ \\ \& A BELEHU \\ Armauer Hansen Research Institute (AHRI), PO Box 1005, Addis \\ Ababa, Ethiopia; $\dagger$ University of Oslo, Institute for Experimental \\ Medical Research, Ullevaal Hospital, Oslo 1, Norway
}

\section{Accepted for publication 17 March 1983}

\begin{abstract}
Summary Nerve damage is common in leprosy although the mechanisms involved are poorly understood. We have isolated myelin proteins from bovine sciatic nerves and used them to detect sensitization to these antigens as a possible mechanism for nerve damage in leprosy patients. These proteins as well as Mycobacterium leprae sonicate were used in an in vitro lymphocyte stimulation assay and data from leprosy patients compared to healthy contacts who served as controls. Furthermore, for each patient a correlation between the lymphoproliferative response to the myelin proteins and clinical parameters of nerve damage was looked for.

Our results do not show any differences between the patients and control subjects in their responses to myelin proteins. There was also no correlation between these responses and any clinical parameter of nerve damage or classification of the patient. Myelin basic protein, $\mathrm{P}_{1}$, stimulated lymphocytes from all individuals studied and behaved like a mitogen. A significant positive correlation was found between lymphocyte stimulation to $M$. leprae and the number of enlarged peripheral nerves.

It is felt that unlike experimental allergic neuritis or encephalomyelitis, leprosy neuropathy is most likely not mediated via an autoimmune sensitization to myelin proteins. Our negative findings could, however, be due to lymphocyte trapping in nerve lesions. Furthermore, the possibility that autosensitization to other nerve components, e.g. non-myelin, may be involved in the pathogenesis of some nerve lesions in leprosy cannot be ruled out. Our studies, however, offer further support to the concept that hypersensitivity to intraneurally located $M$. leprae antigens is the main mechanism whereby nerve damage is produced in leprosy.
\end{abstract}

* Part I of this paper will appear in Int J Lepr, 1983; in press as: Mshana R N, Harboe M, Stoner GL, Hughes RAC, Kadlubowiski M, Belehu A. Immune responses to bovine neural antigens in leprosy patients. I. Absence of antibodies to an isolated myelin protein. 


\section{Introduction}

In animals the involvement of cell-mediated immune responses to myelin proteins in the pathogenesis of peripheral neuropathy has been studied. ${ }^{1-3}$ In this model, experimental allergic neuritis (EAN), the antigen involved has been shown to be a myelin basic protein called $\mathrm{P}_{2} \cdot{ }^{4-6}$ Injection of this protein with complete adjuvant (although even without adjuvant: Hughes RAC, personal communication) usually leads to EAN in susceptible animals. ${ }^{6}$ Histologically, EAN lesions are characterized by perivascular lymphocytic and macrophage infiltration accompanied by demyelination. ${ }^{1-7}$ Myelin basic protein, $\mathrm{P}_{1}$, has been shown to be encephalitogenic in animals inducing a disease of the central nervous system. Although electrophysiological changes in peripheral nerves can be seen in this disease ${ }^{8}$ the peripheral nerves are not the primary target of the inflammatory cells. Since leprosy seems to spare the central nervous system, it seems unlikely that an autoimmune attack to $P_{1}$ might be involved in the pathogenesis of leprosy nerve damage. Myelin protein, $\mathrm{P}_{0}$, is the major protein component of the peripheral nerves. Its role in the induction of autoimmune peripheral neuropathies has not been well studied.

Segmental demyelination is a frequent finding in leprosy especially early in the disease evolution. ${ }^{9-12}$ In these instances, demyelination has been reported even in the absence of morphologically definable Mycobacterium leprae in situ. ${ }^{9,10,12}$ Failure to detect definable $M$. leprae in nerves which show changes consistent with early leprosy might indicate that either intact bacilli are not absolutely necessary for the pathogenesis of the early changes or that some factors produced at a distance, e.g. autoantibodies or enzymes, are involved.

In established leprosy, especially in the tuberculoid end of the spectrum, lymphocytic infiltration and granulomatous destruction of the nerve tissue in the extreme paucity of $M$. leprae is the characteristic finding. So far it has been assumed that the cellular infiltration is a result of hypersensitivity to intraneural bacillary antigens. ${ }^{13,14}$ Since $M$. leprae has powerful adjuvant activity,${ }^{15}$ it has been suggested that autosensitization to myelin proteins might perpetuate nerve damage in these patients. ${ }^{10,16-18}$ To date no work has been done to confirm this.

This paper describes results of studies on the role of cellular responses to isolated myelin bovine proteins in the pathogenesis of leprosy neuropathy.

\section{Materials and methods}

\section{ANTIGENS}

Mycobacterium leprae were isolated from a single subcutaneous nodule of an untreated lepromatous leprosy patient. ${ }^{13}$ After washing, the bacilli were suspended in $0 \cdot 1 \mathrm{M} \mathrm{NaCl}$ at a concentration of $1 \times 10^{7}$ bacilli $/ \mathrm{ml}$ before being sonified 
for 1 hour. The sonicate was centrifuged at $45,000 \mathrm{~g}$ for 30 minutes and the supernatant used for the study.

Myelin proteins, $\mathrm{P}_{1}, \mathrm{P}_{0}$ and $\mathrm{P}_{2}$ were isolated from freshly dissected bovine sciatic nerves. Nerves were collected in ice-cold isotonic saline containing 800 $\mathrm{KIU} / \mathrm{ml}$ Aprotonin (Trasylol ${ }^{\circledR}$; Bayer, Leverkusen, Germany) and cleaned of fat and connective tissue. They were then minced and homogenized in $0.31 \mathrm{~m}$ sucrose to give a $5 \% \mathrm{w} / \mathrm{v}$ homogenate which was layered on $0.85 \mathrm{~m}$ sucrose and centrifuged at $10^{5} \mathrm{~g}$ for 1 hour. Myelin proteins in the interphase were collected and resuspended in $0.31 \mathrm{M}$ sucrose and again layered on $0.85 \mathrm{M}$ sucrose and centrifuged to purify them. Myelin proteins were then separated by the method of Uyemura et al. ${ }^{19}$

\section{LYMPHOCYTE TRANSFORMATION TEST}

Lymphocytes were isolated from venous blood using Böyum's technique. ${ }^{20}$ Lymphocytes were then resuspended in RPMI-1640 containing penicillin, streptomycin, glutamine and fortified with $20 \%$ normal human serum to a final concentration of $5 \times 10^{5}$ cells $/ \mathrm{ml}$. $200 \mu \mathrm{l}$ aliquots were then pippetted out into microtitre culture plates and incubated with the antigens in an incubator at $37^{\circ} \mathrm{C}$ with a $5 \% \mathrm{CO}_{2}, 100 \%$ humidity atmosphere. Eighteen hours before harvesting cultures were pulsed with ${ }^{3} \mathrm{H}$-thymidine. Cells were then harvested and counted in a liquid scintillation counter.

\section{CLINICAL EXAMINATION}

Prior to intake, patients were thoroughly examined and special attention paid to peripheral nerve enlargement and/or tenderness. The nerves examined in each patient were ulnar nerve immediately above the elbow, the posterior tibial nerve between the internal malleolus and the point of the heel, the common peroneal nerve where it winds round the neck of the fibula and the great auricular nerve. These were all done by one examiner. All patients were untreated prior to intake.

\section{STATISTICS}

Results of radioactivity in cultures without antigen were subtracted from those with the antigen. The resulting figures were then $\log _{10}$ transformed and statistical analysis done by the unpaired Student's $t$-test.

\section{Results}

Fifteen normal healthy leprosy contacts and 29 leprosy patients participated in the study. The normal contacts were either institute or hospital staff and have had 
more than 5 years of direct contact with leprosy patients. None of these, however, on clinical examination, had any signs or symptoms of leprosy. The leprosy patients consisted of 14 borderline tuberculoid (BT) and 15 patients with either borderline lepromatous or lepromatous leprosy. The diagnosis was confirmed by histological examination of skin biopsies according to the Ridley-Jopling scale. ${ }^{21}$ The ages of the patients and controls were matched and ranged from 18 to 40 years.

Myelin proteins were all used on a fixed concentration giving $20 \mu \mathrm{g}$ protein $/ \mathrm{ml}$ of culture and harvested on day 6 . This was based on the dose response curves (Figure 1a) and time response curves (Figure 1b) of normal healthy contacts.

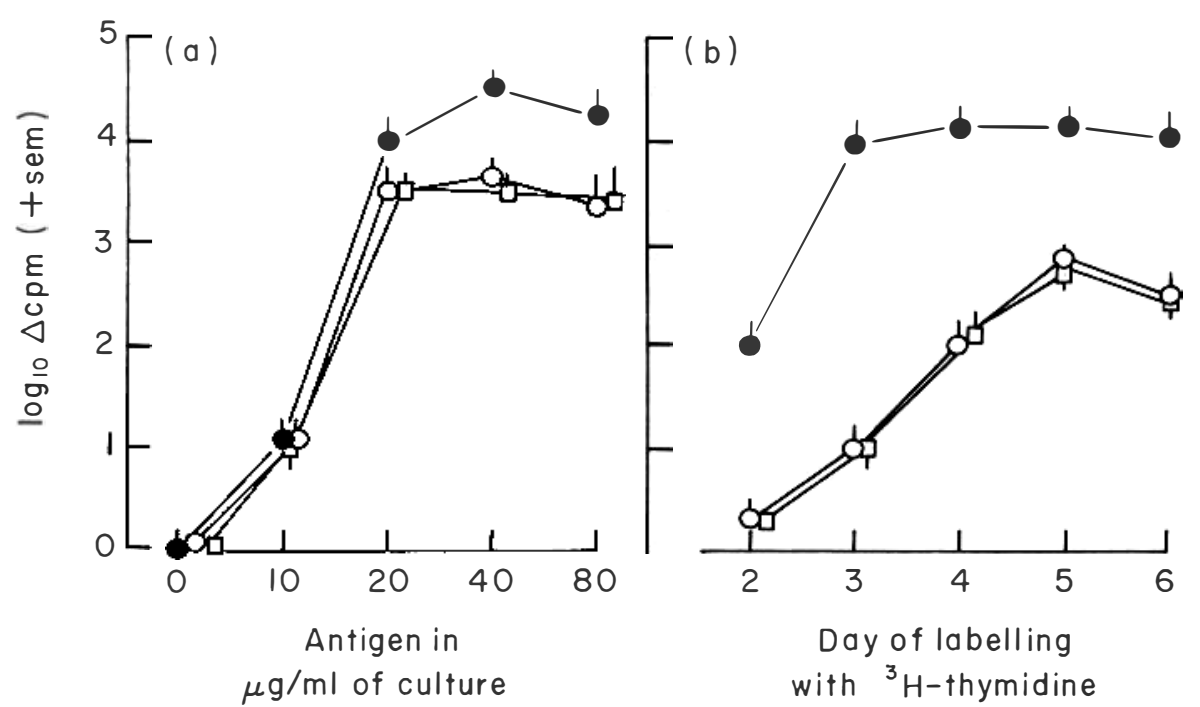

Figure 1. (a) Dose response curves for in vitro lymphocyte stimulation to bovine peripheral nerve myelin proteins in healthy individuals $(n=15)$. All cultures harvested at day 6. (b) Time-response curves for in vitro lymphocyte stimulation to bovine peripheral nerve myelin proteins in healthy individuals $(n=15)$. All tests done with $20 \mu \mathrm{g}$ antigen/ml of culture. $\bullet, \mathrm{P}_{1}, \mathrm{O}, \mathrm{P}_{0}, \square, \mathrm{P}_{2}$.

Note that the response of the normal lymphocytes to myelin protein, $\mathrm{P}_{1}$, is significantly higher than the rest starting from day 3 when using $20 \mu \mathrm{g} / \mathrm{ml}$ (Figure $1 \mathrm{~b})$. The response attained at this time shows only slight increase with prolonged culture. No newborn cells were used to confirm whether this protein actually is mitogenic or not. Figure 2 shows that there are no significant differences between the different study groups in response to individual myelin proteins, whereas patients with lepromatous type of leprosy had a significantly lower response to Mycobacterium leprae. The correlations between the major neural findings and individual responses to the antigens studied are shown in Figure 3. The only correlation was found to be between in vitro lymphoproliferative response to $M$. leprae and the number of enlarged peripheral nerves, so that patients with high 

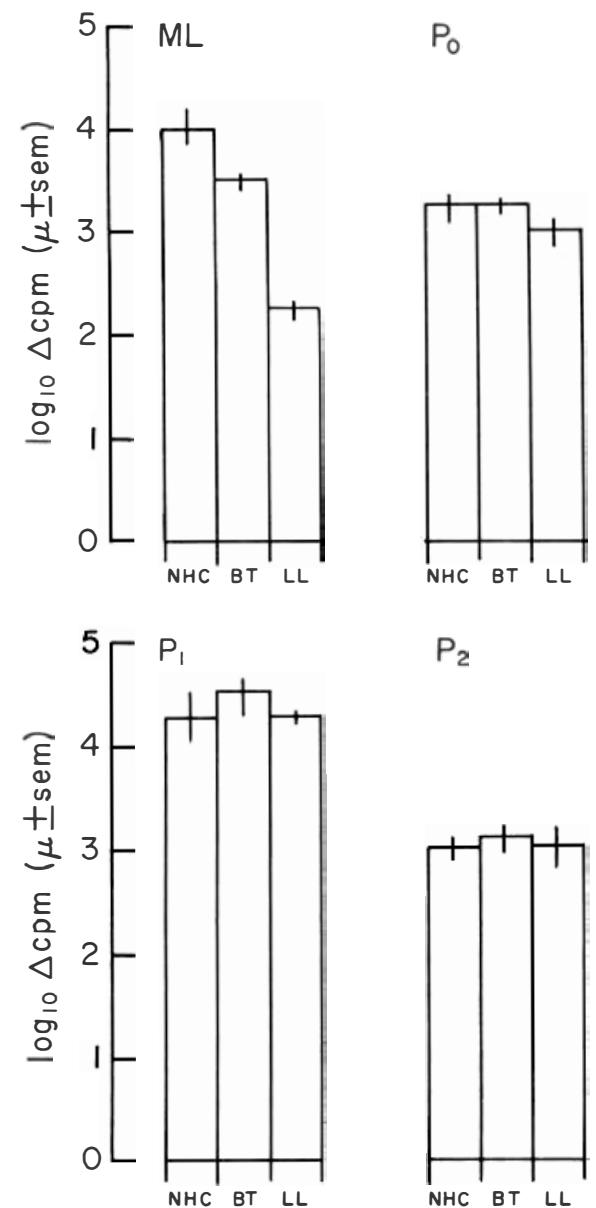

$P_{2}$

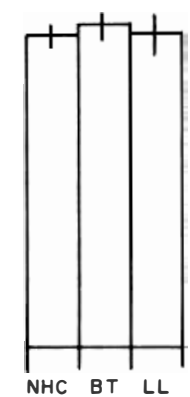

Figure 2. In vitro lymphocyte stimulation test to various antigens in healthy controls and leprosy patients. Myelin proteins were used at final concentration of $20 \mu \mathrm{g} / \mathrm{ml}$ of culture while the Mycobacterium leprae antigen was a sonicate preparation of $1 \times 10^{7}$ bacilli $/ \mathrm{ml}$. ML, M. leprae; $\mathrm{P}_{0}, \mathrm{P}_{1}$ and $\mathrm{P}_{2}$ are bovine peripheral nerve myelin proteins; $\mathrm{NHC}$, normal healthy controls; $\mathrm{BT}$, borderline tuberculoid leprosy patients; LL, lepromatous leprosy patients.

responses tended to have more enlarged peripheral nerves $(r=0.8 ; t=6.9$; $P<0 \cdot 001)$. No correlation exists between in vitro lymphocyte stimulation to myelin proteins and number of enlarged peripheral nerves. Figure 4 shows that no correlation exists between in vitro lymphocyte stimulation to $M$. leprae and stimulation to the various myelin proteins.

\section{Discussion}

Proof had already been produced to show that in susceptible animals, peripheral 

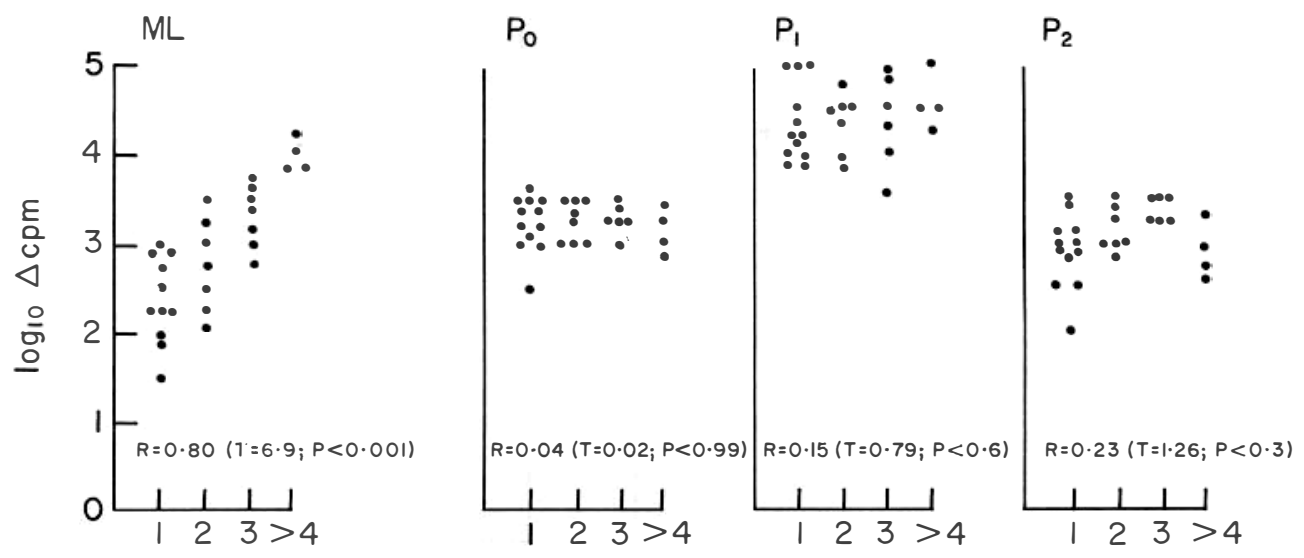

Number of enlarged peripheral nerves

Figure 3. Correlation between lymphocyte stimulation to various antigens and the number of enlarged peripheral nerves judged by clinical examination in leprosy patients. Each dot represents an individual patient. (Abbreviations are as in Figure 2.)

neuropathy could be induced via autoimmune mechanisms. Although the exact role of each component of the immune response has not been clearly delineated, the consensus of opinion at the moment indicates that the main pathology is mediated by cellular mechanisms. Histologically this neuropathy is characterized by florid perivascular lymphocyte and macrophage infiltration with marked myelin loss. Macrophages can be seen to strip myelin sheaths and destroy them by extracellular vesiculation. How macrophages do this is not known with certainty, but release of enzymes is thought to be involved. ${ }^{22,23} \mathrm{~A}$ conspicuous feature is that in this disease intraneural granuloma formation is not seen; perhaps because of the acute nature of the disease. In borderline tuberculoid and tuberculoid leprosy, the involved nerves show typical features of well matured epithelioid cell granulomas. Although perivascular infiltration can be seen in some areas, it is not a prominent feature except during acute reversal reactions (unpublished observations). Although the granulomas are thought to be directed towards $M$. leprae, in certain sites areas of segmental demyelination can be seen in the absence of morphologically definable Mycobacterium leprae, the intensity of demyelination being roughly proportional to the cellular infiltrate. ${ }^{11}$ In these instances it is tempting to suggest that an autoimmune cellular reaction is propagating the nerve damage. ${ }^{10,16-18}$ In order to shed light into this problem, however, techniques to demonstrate $M$. leprae antigens rather than the whole bacillus will have to be employed. This is especially important since Bjune et al..$^{13}$ have indicated that $M$. leprae cytoplasmic antigens rather than the whole bacillus may be more important in the pathogenesis of leprous neuropathy. It must be stated that the conventional techniques to stain $M$. leprae do not stain released antigens. By using an immunologically based technique, we were able to detect mycobacterial 

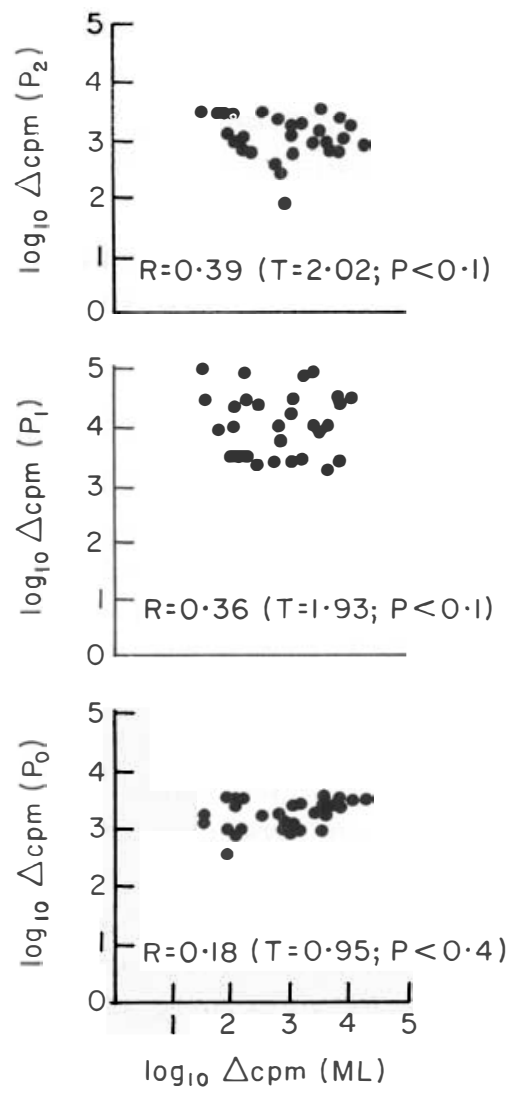

Figure 4. Correlation between lymphocyte stimulation to Mycobacterium leprae (ML) and stimulation to various myelin proteins $\left(\mathrm{P}_{0}, \mathrm{P}_{1}\right.$ and $\left.\mathrm{P}_{2}\right)$ in leprosy patients. Each dot represents an individual patient. (Abbreviations are as in Figure 2.)

antigens in a number of biopsies which had no morphologically identifiable acid-fast bacilli. ${ }^{24}$ By applying the technique to peripheral nerve biopsies we have found similar findings (submitted). These findings thus support the concept that peripheral nerve damage in leprosy is a result of immunological recognition of intraneural $M$. leprae antigens. Furthermore, in the present study a correlation could only be seen between in vitro lymphoproliferative response to M. leprae and the number of enlarged peripheral nerves (Figure 4). Repeated delayed type hypersensitivity reactions to intraneural antigens could explain these findings. It is unlikely that this correlation was due to the duration of the disease.

Myelin proteins or their fragments are expected to be released and come into contact with the immune system in a disease where demyelination is frequent. In leprosy, one would then expect autosensitization to these proteins since $M$. leprae has powerful adjuvant activity. ${ }^{15}$ Our data, however, do not indicate this to be the case. The possibility of lymphocyte trapping at lesional areas can, however, not be easily ruled out. Indeed a discrepancy between disease severity and in vitro 
lymphoproliferative responses to $\mathrm{P}_{2}$ can be seen in animals with experimental allergic neuritis, and in earlier studies similar observations had been reported in animals with experimental allergic encephalomyelitis (EAE). ${ }^{25}$ Absence of the in vitro correlate of cell-mediated immunity to myelin proteins, therefore, does not offer absolute or conclusive evidence for lack of involvement of autoimmune mechanisms in the perpetuation of leprosy neuropathy. Patients with the Guillain-Barré syndrome have been shown to have cell-mediated immune response against peripheral nerve extracts ${ }^{27,28}$ but unexpectedly not to $\mathrm{P}_{2}{ }^{29}$ indicating that an antigen not yet described might be the target of the immune attack. A similar situation could very well be operating in leprosy neuropathy. Although determinant(s) for cell-mediated immune responses to myelin proteins might differ from species to species as has been suggested for the humoral response to myelin protein, $\mathrm{P}_{2}{ }^{26}$ it is unlikely that this could be the reason for our negative findings since both EAE and EAN belong to the group of autoimmune diseases which are organ specific but species non-specific.

Degeneration of unmyelinated nerve fibres is an essential feature of nerve damage in leprosy. In EAN demyelination is the characteristic finding but there is little or no involvement of unmyelinated fibres. Both granulomas and unmyelinated fibre degeneration have been produced by skin testing rabbits previously sensitized with human sensory peripheral nerve..$^{30,31}$ The skin-test antigen producing unmyelinated fibre degeneration and granuloma formation resides in the non-myelin fraction of the sensory nerve and seems to be a component of Schwann cell membrane. ${ }^{32}$ It is thus possible that nerve damage in leprosy, especially the sensory nerve damage, may be due to an autoimmune response to a non-myelin component in sensory nerves. ${ }^{33}$

Although lymphocyte stimulation test cannot strictly be used to assess immunological relatedness between antigens, it is interesting to note that no correlation was found between responses to $M$. leprae and those of myelin proteins. Indirectly, this would suggest that no cross-reactions, at least as far as this system is concerned, can be found between M. leprae and myelin proteins. This implies that an immune response directed against $M$. leprae could not damage myelin proteins in the absence of intraneural $M$. leprae. Indeed this observation explains the clinical findings of healthy nerves in individuals in leprosy endemic areas despite their having hypersensitivity to $M$. leprae. Our data thus contradicts previous findings which were based on using skin testing and reporting cross-reactions between mycobacteria and myelin proteins ${ }^{34}$ and supports those of Stoner et al. ${ }^{35}$ who found no such cross-reactions.

Myelin protein, $\mathrm{P}_{1}$, stimulated lymphocytes from both leprosy patients and healthy contacts (Figure 2). This finding is in line with that reported previously. ${ }^{36}$ This would indicate that either there is a low level of sensitization to this antigen ${ }^{37}$ or that $\mathrm{P}_{1}$ is mitogenic. ${ }^{36}$ Our data on studies of the kinetics of this reaction where a definite response is seen after 3 days of culture would tend to support the latter (Figure 1b). Further studies on this protein are, however, needed especially in 
view of the fact that this protein causes EAE which is a disease with certain similarities to multiple sclerosis.

Other mechanisms have been proposed to be involved in the pathogenesis of leprosy neuropathy. Peri- and intraneural inflammation secondary to intraneural antigen has been shown to lead to primary demyelination. ${ }^{38}$ In high-resistant leprosy, hypersensitivity to and intraneural $M$. leprae co-exist, thus closely mimicking an experimental animal model. ${ }^{38}$ Hypersensitivity to these antigens may thus be responsible for part of the nerve damage. ${ }^{13,14}$ We have recently been able to produce direct evidence for this mechanism by injecting $M$. leprae intraneurally into animals made hypersensitive to $M$. leprae ${ }^{39}$ The histology of the nerve damage seen was strikingly similar to that of human nerves during reversal reaction.

\section{Acknowledgements}

We wish to thank Dr R A C Hughes, Guy's Hospital, London for his generous gift of myelin basic protein, $\mathrm{P}_{2}$, and fruitful discussion. Dr C L Crawford, Charing Cross Hospital, London is acknowledged for extremely useful discussions and encouragement. Physicians at the All Africa Leprosy Rehabilitation and Training Centre (ALERT) referred patients to us. In particular we would like to thank Dr J G Andersen who carefully examined and referred patients to us.

We thank W/o Mulunesh Negash for typing the manuscript.

The Armauer Hansen Research Institute is supported by the Norwegian and Swedish Save the Children foundations.

\section{References}

${ }^{1}$ Abramsky O, Teitelbaum D, Arnon R. Experimental allergic neuritis induced by a basic neuritogenic protein $\left(\mathrm{P}_{1} \mathrm{~L}\right)$ of human peripheral nerve origin. Eur J Imm, 1977; 7: 213-17.

2 Arnason BGW, Chelmicko-Szorc E. Passive transfer of experimental allergic neuritis in Lewis rats by direct injection of sensitized lymphocytes into sciatic nerve. Acta Neuropath (Berl), 1972; 22: 1 .

3 Astrom KE, Waksman $\mathrm{BH}$. The passive transfer of experimental allergic encephalomyelitis and neuritis with living lymphoid cells. $J$ Path Bact, 1962; 83: 89.

${ }^{4}$ Kadlubowski M, Hughes RAC. Identification of the neuritogen for experimental allergic neuritis. Nature, 1979; 277:140-1.

${ }^{5}$ Kadlubowski M, Hughes RAC, Gregson NA. Experimental allergic neuritis in the Lewis rat: characterization of the activity of the peripheral nerve myelin and its major basic protein, $\mathrm{P}_{2}$. Brain Res, 1980; 184: 439-54.

${ }^{6}$ Kadlubowski M, Hughes RAC. The neuritogenicity and encephalitogenecity of $\mathrm{P}_{2}$ in the rat, guinea pig and rabbit. $J$ Neurol $S c i, 1980 ; 48$ : 171-8.

${ }^{7}$ Lampert PW. Mechanism of demyelination in experimental allergic neuritis. Electron microscopic studies. Lab Invest, 1969; 20: 127.

8 Pender MP, Sears TA. Conduction block in the peripheral nervous system in experimental allergic encephalomyelitis. Nature, 1982; 296: 860-2. 
9 Boddingius J. D.Phil. Thesis, Oxford, 1977.

${ }^{10}$ Dastur DK, Porwal GL, Shah JS, Revankar CR. Immunological implications of necrotic, cellular and vascular changes in leprous neuritis: light and electron microscopy. Lepr Rev, 1982; 53: 45-65.

${ }^{11}$ Finlayson MH, Bilbao JM, Lough JO. The pathogenesis of the neuropathy in dimorphous leprosy: electron microscopic and cytochemical studies. J Neuropath Exp Neurol, 1974; 33: 446.

12 Shetty VP, Mehta LN, Irani PF, Antia NH. Study of evolution of nerve damage in leprosy: I. Lesions of the index branch of the radial cutaneous nerve in early leprosy. Lepr India, 1980; 52: 5-18.

13 Bjune G, Barnetson R StC, Ridley DS, Kronvall G. Lymphocyte transformation test in leprosy: correlation of the response with inflammation of lesions. Clin exp Imm, 1976; 25: 85-94.

14 Godal T, Myrvang B, Samuel DR, Ross WF, Løfgren M. Mechanisms of 'reactions' in borderline tuberculoid (BT) leprosy. Acta Path Microbiol Scand A, Suppl, 1973; 263: $45-53$.

15 Stewart-Tull DES, Daries M. Adjuvant activity to Mycobacterium leprae. Infect Imm, 1972; 6: 909.

${ }^{16}$ Dastur DK. The peripheral neuropathology of leprosy. In Symposium on Leprosy. Antia NH, Dastur DK (eds), Bombay University Press, 1967; pp. 57-71.

17 Dastur DK, Dabholkar AS. Histochemistry of leprous nerves and skin lesions: acid phosphatase. J Pathol, 1974; 113: 69-77.

18 Dastur DK. In Scientific Approaches to Clinical Neurology. Goldenholn ES, Appel SH (eds), New York: Lea and Febriger, 1977; pp. 1456-93.

19 Uyemura K, Tobari C, Hirano S, Tsukada Y. Comparative studies on the myelin proteins of bovine peripheral nerve and spinal cord. J Neurochem, 1972; 19: 2607-14.

${ }^{20}$ Böyum A. Isolation of mononuclear cells and granulocytes from human blood. Scand J Clin Lab Invest, Suppl, 1968; 21: 97.

${ }^{21}$ Ridley DS, Jopling WH. The classification of leprosy according to immunity. A group system. Int $J$ Lepr, 1966; 34: 255-73.

22 Bloom BR. In Immunological Aspects of Leprosy, Tuberculosis and Leishmaniasis. Humber DP (ed), Amsterdam-Oxford-Princeton: Excerpta Medica, 1981; pp. 85-6.

${ }^{23}$ Cammer W, Bloom BR, Norton WT, Gordon S. Degradation of basic protein in myelin by neutral proteases secreted by stimulated macrophages: a possible mechanism of inflammatory demyelination. Proc Natl Acad Sci USA, 1978; 75: 1552.

${ }^{24}$ Mshana RN, Belehu A, Stoner GL, Harboe M, Haregewoin A. Demonstration of mycobacterial antigens in leprosy tissues. Int J Lepr, 1982; 50: 1-10.

25 Alvord EC, Hruby S, Sires LR. Degradation of myelin basic protein by cerebrospinal fluid: preservation of antigenic determinants under physiological conditions. Ann Neurol, 1979; 6: 474-82.

${ }^{26}$ Sarvas HO, Milek DJ, Weise MJ, Varnow TB, Fudenberg HH, Brostoft SW. Radioimmunoassay for the $\mathrm{P}_{2}$ protein of bovine peripheral nerve myelin. $J$ Imm, 1980; 124: 557.

${ }^{27}$ Knowles M, Saunders M, Curie S, Walter IN, Field EH. Lymphocyte transformation in the Guillain-Barré syndrome. Lancet, 1969; 2: 1168.

${ }^{28}$ Rocklin RE, Sheremata WA, Feldman RG, Kies MW, David JR. Cellular responses in Guillain-Barré syndrome and multiple sclerosis. New Engl J Med, 1971; 284: 803.

${ }^{29}$ Iqbal A, Oger JJ-F, Arnason BGW. Cell-mediated immunity in idiopathic polyneuritis. Ann Neurol Suppl, 1981; 9: 65.

${ }^{30}$ Crawford CL, Hardwicke PMD, Evans DHL, Evans EM. Granulomatous hypersensitivity induced by sensory peripheral nerves. Nature, 1977; 265: 457-9.

${ }^{31}$ Crawford CL, Hardwicke PMD. Ultrastructural features of epithelioid cell granuloma induced by intradermal injection of xenogeneic nerve tissue. J Pathol, 1978; 125: 107. 
${ }^{32}$ Hardwicke PMD, Crawford CL, Hüvös P. Skin lesions induced by sensory peripheral nerve are not due to an additional myelin protein. $J$ Neurochem, 1977; 29: 371-3.

${ }^{33}$ Crawford CL, Evans DHL, Evans EM. Experimental allergic neuritis induced by sensory nerve myelin may provide a model for non-lepromatous leprosy. Nature, 1974; 251: 223-5.

${ }^{34}$ Vandenbark AA, Burger DR, Vetto RM. Cell-mediated immunity in experimental allergic encephalomyelitis: cross-reaction between myelin basic protein and mycobacterial antigen. Proc Soc Exp Biol Med, 1975; 148: 1233.

35 Stoner GL, Bronsnan CF, Wisniewsiki HM, Bloom BR. Studies on demyelination by activated lymphocytes in the rabbit eye. I. Effects of a mononuclear cell infiltrate induced by products of activated lymphocytes. $J$ Imm, 1977; 118: 2094-2102.

${ }^{36}$ Hughes RAC, Gray IA, Clifford-Jones R, Stern MA. Lymphocyte transformation in the presence of myelin basic protein in multiple sclerosis and control subjects. Acta Neurol Scand, 1979; 60: 65-76.

37 Edington TS, Delissio DJ. The assessment by immunofluorescent methods of humoral anti-myelin antibodies in man. $J$ Imm, 1970; 105: 240-55.

38 Wisniewsiki HM, Bloom BR. Primary demyelination as a non-specific consequence of a cell-mediated immune reaction. J exp Med, 1975; 141: 346-59.

39 Mshana RN, Humber DP, Harboe M, Belehu A. Nerve damage following intraneural injection of Mycobacterium leprae into rabbits presensitized to mycobacteria. Clin exp Imm, 1983; 52: (in press). 